\title{
Exsolution of Nickel Nanoparticles from Mixed-Valence Metal Oxides: A Quantitative Evaluation by Magnetic Measurements
}

Tinti, Victor B.; Marani, Debora; Ferlauto, Andre S.; Fonseca, Fabio Coral ; Esposito, Vincenzo; Zanetti De Florio, Daniel

Published in:

Particle \& Particle Systems Characterization

Link to article, DOI:

$10.1002 / p p s c .201900472$

Publication date:

2020

Document Version

Peer reviewed version

Link back to DTU Orbit

Citation (APA):

Tinti, V. B., Marani, D., Ferlauto, A. S., Fonseca, F. C., Esposito, V., \& Zanetti De Florio, D. (2020). Exsolution of Nickel Nanoparticles from Mixed-Valence Metal Oxides: A Quantitative Evaluation by Magnetic Measurements. Particle \& Particle Systems Characterization, 37(2), [1900472]. https://doi.org/10.1002/ppsc.201900472

\section{General rights}

Copyright and moral rights for the publications made accessible in the public portal are retained by the authors and/or other copyright owners and it is a condition of accessing publications that users recognise and abide by the legal requirements associated with these rights.

- Users may download and print one copy of any publication from the public portal for the purpose of private study or research.

- You may not further distribute the material or use it for any profit-making activity or commercial gain

- You may freely distribute the URL identifying the publication in the public portal 


\section{Particle and Particle Systems Characterization \\ Exsolution of nickel nanoparticles from mixed-valence metal oxides: a quantitative evaluation by magnetic measurements \\ --Manuscript Draft--}

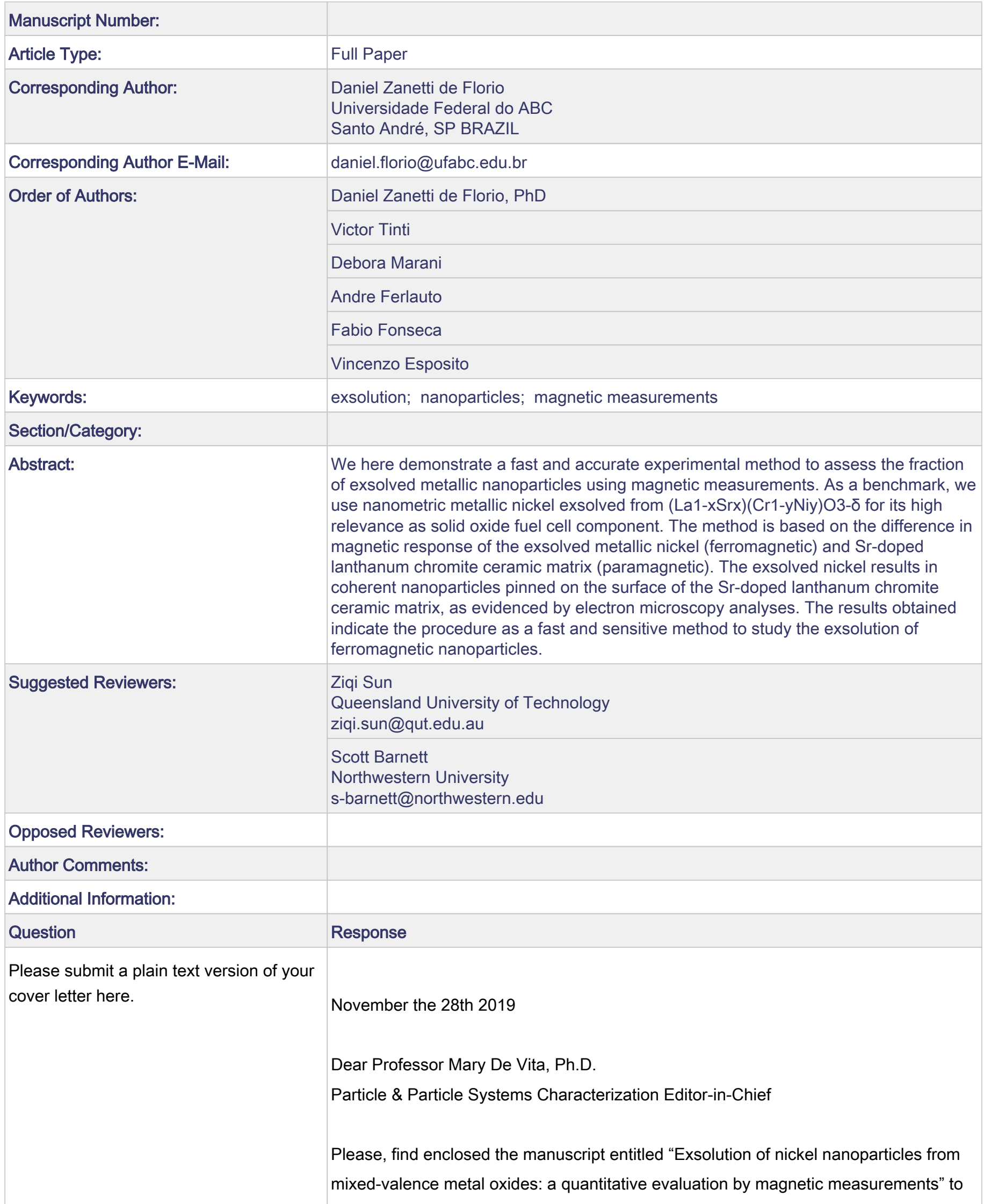




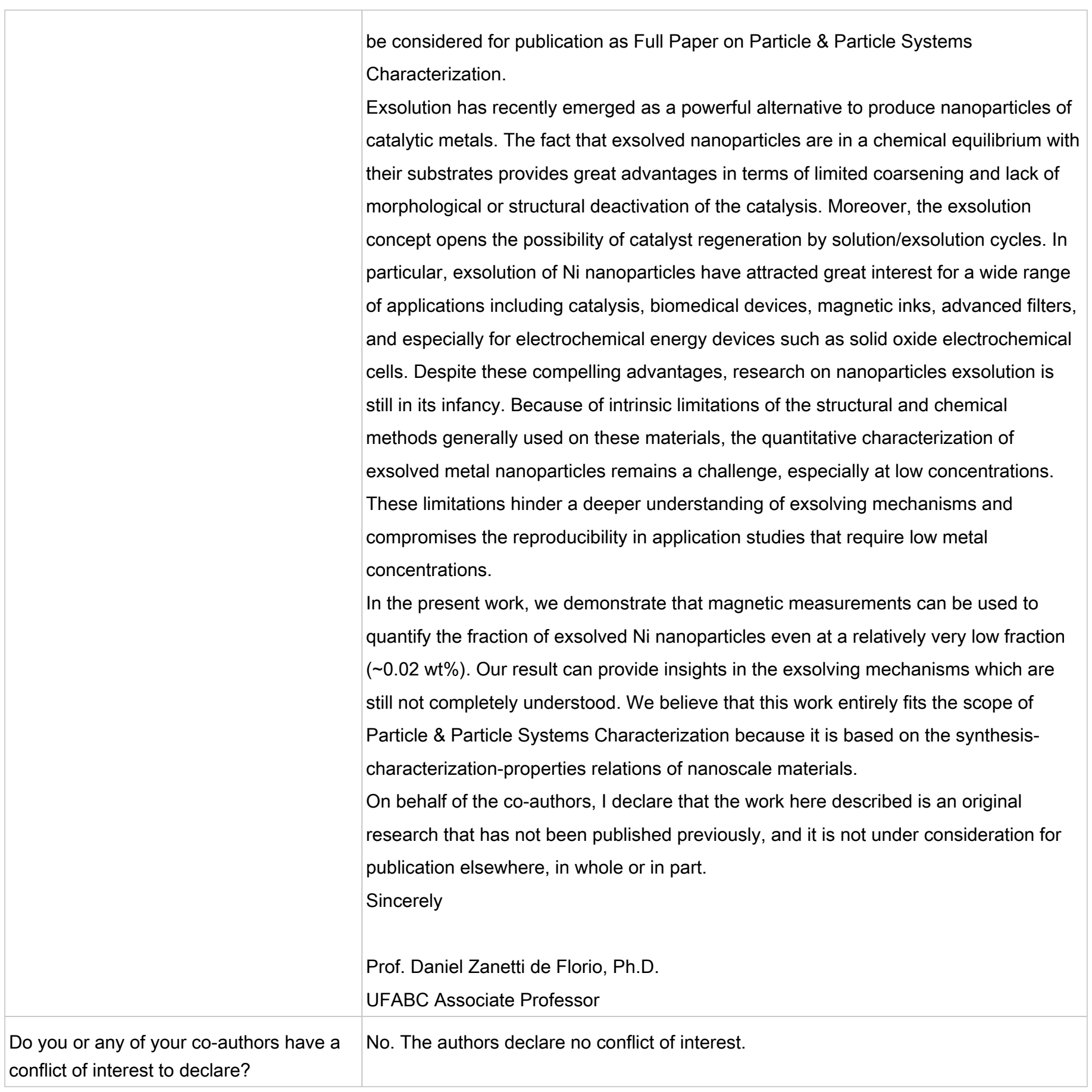


Exsolution of nickel nanoparticles from mixed-valence metal oxides: a quantitative evaluation by magnetic measurements

\author{
Victor B. Tinti ${ }^{1}$, Debora Marani ${ }^{1}$, Andre S. Ferlauto ${ }^{1}$, Fabio C. Fonseca $^{2}$, Vincenzo \\ Esposito $^{3}$, Daniel Z. de Florio ${ }^{1}$ \\ ${ }^{1}$ Federal University of ABC, CECS, Santo André, SP, Brazil \\ ${ }^{2}$ Nuclear and Energy Research Institute, CCCH, São Paulo, SP, Brazil \\ ${ }^{3}$ DTU Energy, Roskilde, Denmark
}




\section{ABSTRACT}

We here demonstrate a fast and accurate experimental method to assess the fraction of exsolved metallic nanoparticles using magnetic measurements. As a benchmark, we use nanometric metallic nickel exsolved from $\left(\mathrm{La}_{1-\mathrm{x}} \mathrm{Sr}_{\mathrm{x}}\right)\left(\mathrm{Cr}_{1-\mathrm{y}} \mathrm{Ni}_{\mathrm{y}}\right) \mathrm{O}_{3-\delta}$ for its high relevance as solid oxide fuel cell component. The method is based on the difference in magnetic response of the exsolved metallic nickel (ferromagnetic) and Sr-doped lanthanum chromite ceramic matrix (paramagnetic). The exsolved nickel results in coherent nanoparticles pinned on the surface of the Sr-doped lanthanum chromite ceramic matrix, as evidenced by electron microscopy analyses. The results obtained indicate the procedure as a fast and sensitive method to study the exsolution of ferromagnetic nanoparticles. 


\section{INTRODUCTION}

Nanomaterials are increasingly applied in a number of key technologies [1,2]. Eminent examples of the strategic use of nanomaterials include biomedical devices [3], inks [4,5], advanced filters [6] and semiconductors [7]. The wide diffusion of the nanomaterials is mainly due to their unique features such as the nano-confinement, high surface-to-volume ratio, and a large specific surface area $[1,8]$. In catalysis, an extensive reactive surface area allows for a significant increment of the active sites and of their exposure to the reactants $[8,9]$. Typically, to maximize the exposed surface area and stabilize the nanoparticles against agglomeration, catalysts are dispersed over adequate supports, that can be either inert or can participate in the catalytic process [10-12]. The large majority of supported-nanoparticles are prepared by deposition methods (e.g. impregnation) that are very simple, but enable a limited control over critical aspects such as an efficient dispersion of the catalyst [11]. In addition, the prolonged exposure to critical environmental (industrial) conditions (e.g. high temperature) and in the presence of contaminants (e.g. carbon) leads to the deactivation of the catalysts by either agglomeration or coking $[10,11,13]$.

To mitigate the deactivation phenomena, a post-growth procedure, i.e. the redox exsolution, has recently emerged as a reasonable alternative [14-17]. In this route, the catalyst is dissolved as cation into a hosting lattice to produce a solid solution and then exsolved to the surface as socked nanoparticles under reducing atmosphere $[10,15,18]$. The resulting exsolved nanoparticles have been demonstrated to be more resistant to agglomeration, coarsening, and carbon deposition $[10,14,17]$. The strategy has been successfully applied to prepare socked metallic nano-catalysts from various dopedperovskites $[10,14,16,18,19]$. Indeed, the perovskite structure offers an ideal synthetic platform due to its exceptional structural and compositional flexibility [20]. As compared to traditional techniques such as impregnation, the exsolution produces a modest mass fraction of metallic particles [11]. This is mainly associated with the solubility limit of any dopant into a hosting lattice. Yet, high doping ratios might destabilize the matrix and compromise the thermal and chemical stability of the perovskite substrate.

In this context, a precise quantitative analysis of the exsolved nanoparticle is a challenging task. The traditional techniques fail in providing reliable quantitative analysis. For instance, X-ray diffraction, commonly used to determinate and quantifies phases [21,22], is inefficient for small mass fractions ( $<1 \%$ in weight) [22,23]. Scanning (SEM) and Transmission Electron Microscopy (TEM) provide detailed information about 
the size and distribution of nanoparticles [24] and have been commonly used to limited to a very small volume of sample, which demands time-consuming procedures to ensure accurate analyses [10].

In this study, we propose an approach based on magnetic properties for quantitative analysis of the mass fraction of exsolved nanoparticles. Magnetic analyses are relatively fast, very precise and the measurement reflects the properties of the whole sample, thus being reproducible and reliable [27]. Such an approach is based on the different magnetic properties of exsolved nanoparticles as compared to the ceramic matrix, making possible the identification of two distinct magnetic contributions. A similar approach was already used in literature to quantify a phase in a steel alloy [27]. Estimation of the mass fraction for the exsolved nanoparticles is then achieved by analyzing the magnitude of the magnetization. However, magnetic data can be complex, with several transitions and intricated behaviors, being necessary a deep knowledge of the magnetic properties of the components under analysis. Also, magnetic measurements are susceptible to unique interferences, like demagnetization factor and anisotropy [28], being a source of errors

Thus, the materials selected are nickel as the exsolved nanoparticle and strontiumdoped lanthanum chromite as the perovskite host. Nickel is selected because of its relevance as a catalyst in many applications [10,29], and Sr-doped lanthanum chromite exhibits thermal stability at high temperatures $\left(>1600^{\circ} \mathrm{C}\right)$ both in oxidizing and reducing atmospheres to allow exsolution heat treatments without significant changes [30,31]. Moreover, nickel is a canonical ferromagnetic, whereas $\mathrm{Sr}$-doped $\mathrm{LaCrO}_{3} \delta$ is paramagnetic above $\sim 7{ }^{\circ} \mathrm{C}$ [32], with a significantly weaker and distinct magnetic behavior.

\section{EXPERIMENTAL}

Materials with compositions $\left(\mathrm{La}_{1-\mathrm{x}} \mathrm{Sr}_{\mathrm{x}}\right)\left(\mathrm{Cr}_{1-\mathrm{y}} \mathrm{Ni}_{\mathrm{y}}\right) \mathrm{O}_{3}$, with $\mathrm{x}=0.1$, and 0.2 , and $\mathrm{y}=$ 0, 0.1, and 0.2 were prepared via a chemical route based on the Pechini method $[33,34]$.

All starting chemicals were reagent grade $(\geq 99.9 \%)$ by Sigma-Aldrich: lanthanum nitrate $\mathrm{La}\left(\mathrm{NO}_{3}\right)_{3} \cdot 6 \mathrm{H}_{2} \mathrm{O}$, strontium nitrate $\mathrm{Sr}\left(\mathrm{NO}_{3}\right)_{2}$, chromium nitrate $\mathrm{Cr}\left(\mathrm{NO}_{3}\right)_{3} \cdot 9 \mathrm{H}_{2} \mathrm{O}$, and nickel nitrate $\mathrm{Ni}\left(\mathrm{NO}_{3}\right)_{2} \cdot 6 \mathrm{H}_{2} \mathrm{O}$, citric acid (CA) and ethylene glycol (EG). CA and EG were used to promote the complexation of the metallic cations and polymerization of the chelates, respectively. The solvent used to dissolve the nitrates was ultrapure water (Milli$\mathrm{Q}^{\circledR}$ Type 1). The stoichiometric amount of each salt was dissolved in water with $\mathrm{CA}$, and 
the solution was kept under stirring at $80{ }^{\circ} \mathrm{C}$ for 2 hours. After the addition of EG, the temperature was raised to $180{ }^{\circ} \mathrm{C}$ to promote the polymerization. The temperature was kept stable until the formation of a black and brittle polymeric resin [35], which was manually milled to a black fine powder using an agate mortar.

Thermogravimetry (TG) experiments (LABSYS EVO STA, Setaram) were conducted to determine the decomposition temperature of the organic compounds and the crystallization of the desired phase. The samples were heated from room temperature to $1600{ }^{\circ} \mathrm{C}$ at a rate of $10 \% \mathrm{~min}$ in an alumina crucible under synthetic airflow $(125 \mathrm{ml} / \mathrm{min})$. According to the TG results, the materials were then calcinated at $1000{ }^{\circ} \mathrm{C}$ for 1 hour to ensure the complete removal of the organics and the formation of the desired phase.

In order to promote the exsolution of $\mathrm{Ni}$, the as-prepared samples were thermally treated in reducing conditions. Two heat treatments were carried out for the reduction of samples: i) a first one at $750{ }^{\circ} \mathrm{C}$, which is higher than the temperature required to reduce $\mathrm{NiO}$ to $\mathrm{Ni}$ (usually $\sim 300{ }^{\circ} \mathrm{C}$ ) [36], but lower than the temperature typically used to promote exsolution; and ii) at $850^{\circ} \mathrm{C}$, which is commonly used for exsolution $[10,16,26]$. Both reducing treatments were carried out for 9 hours in a tubular furnace with a flow of $50 \mathrm{ml} / \mathrm{min}$ of pure $(\geq 99.999 \%)$ hydrogen.

All samples were characterized by X-ray diffraction (XRD, D8 Focus-Bruker AXS) to determine the structure and phases. The XRD analysis was performed in the $2 \theta$ degree range varying from $20^{\circ}$ to $60^{\circ}$ with a step length of $0.05^{\circ}$ at a rate of $1^{\circ} / \mathrm{min}$, using $\mathrm{CuK}_{\alpha}$ radiation with the equipment operating at $40 \mathrm{kV}$ and $40 \mathrm{~mA}$.

A magnetic properties measurement system (MPMS) by Quantum Design equipped with a vibrating sample magnetometer (VSM) and a superconducting quantum interference device (SQUID) was used for magnetization measurements as a function of the applied magnetic field $(\mathrm{MxH})$ [37]. Magnetic measurements were performed in both as-prepared samples and after thermal treatments in reducing conditions to observe the effect of Ni exsolution on the magnetic properties. The MxH runs were performed at 117 ${ }^{\circ} \mathrm{C}$, which is below the Curie temperature of $\mathrm{Ni}\left(\sim 357^{\circ} \mathrm{C}\right)$ and above the Néel transition temperature of $\mathrm{LaCrO}_{3-\delta}\left(\sim 7^{\circ} \mathrm{C}\right)$ to maximize the response of exsolved ferromagnetic $\mathrm{Ni}$ and to minimize possible influences from the perovskite matrix.

The morphology of the samples was studied using TEM (Transmission Electron Microscopy - HRTEM JEM 2011, JEOL) and FESEM (Field Emission Scanning Electron Microscopy - FESEM JMS-6701F, JEOL). 


\section{RESULTS AND DISCUSSION}

$\mathrm{X}$-rays diffraction patterns reveal that all samples have the orthorhombic phase of the lanthanum chromite with Pnma space group (Figure 1) (ICSD \#51191) [18,32,38]. Nickel solubility limit in $\mathrm{LaCrO}_{3-\delta}$ was reported to be close 20 at.\%; nevertheless, no diffraction peaks of $\mathrm{NiO}$ are detected in the patterns of the investigated samples $[31,38]$. Within the accuracy of XRD, the experimental data indicate that $\mathrm{Ni}$ substituted $\mathrm{Cr}$ in the as-prepared chromite lattice rather than segregated as NiO. Moreover, XRD patterns of both as-prepared (Figure S1) and reduced (Figure 1a and 1b) samples are comparable, confirming the stability of the Sr-doped $\mathrm{LaCrO}_{3-\delta}$ at high temperature under both oxidizing and reducing environments [31,38].

It is not possible to detect diffraction peaks related to metallic nickel for the samples subjected to reducing treatments (Figure 1a and 1b). This is expected because the exsolution process results in relatively low weight fraction of metallic nanoparticles (typically under $1 \mathrm{wt} . \%$ ) [22,23], which is below the detection limit of XRD technique. Indeed, characterizing exsolved nanoparticles is a rather complex task, usually limited to electron microscopy techniques. Imaging techniques are very useful to provide morphological information of the exsolved particles but are statistically limited to the selected observed regions of the samples. 

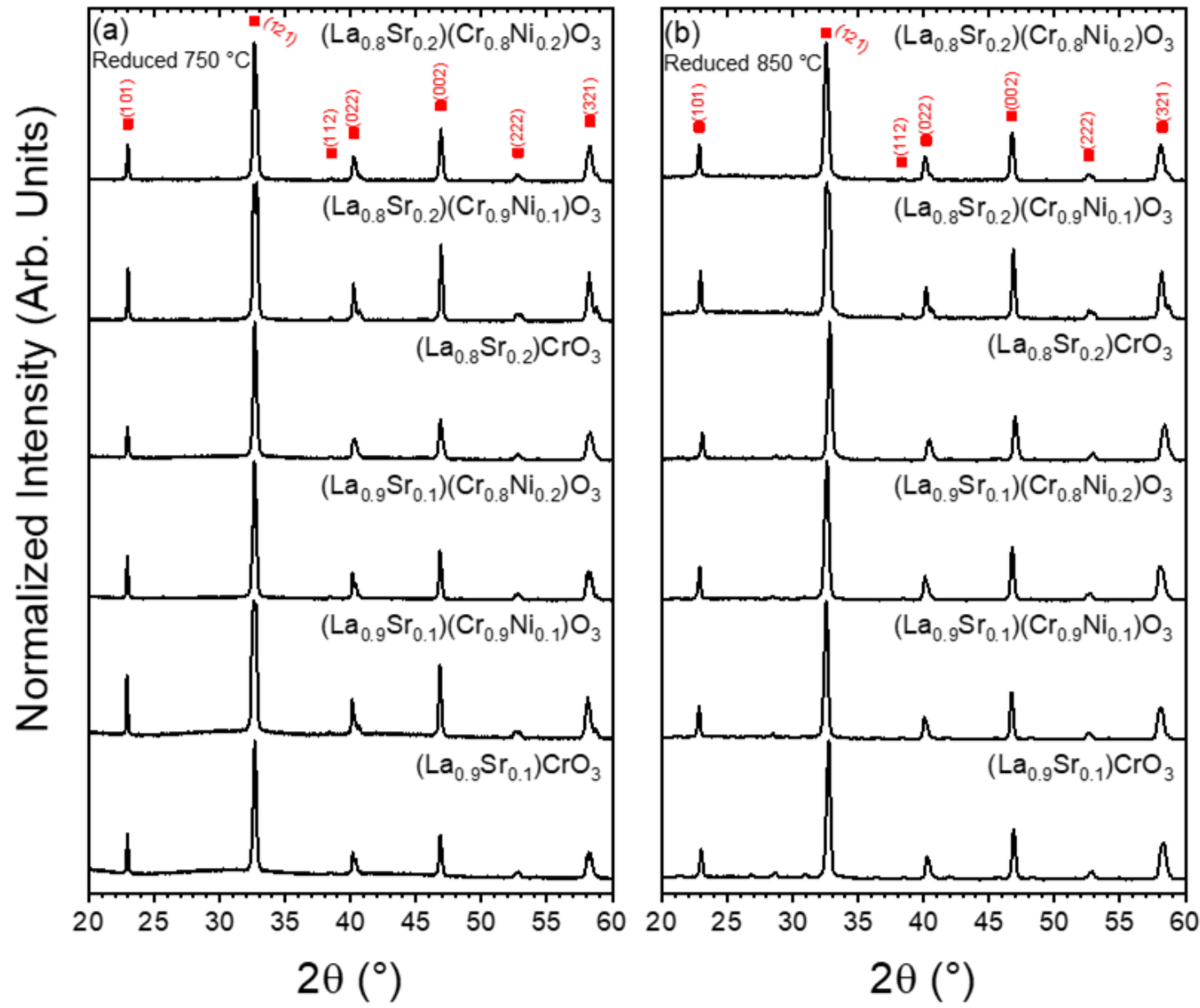

Figure 1: XRD pattern of the samples after reducing treatments at $750{ }^{\circ} \mathrm{C}$ (a) and $850{ }^{\circ} \mathrm{C}$ (b). The red square ( $\square$ ) identifies the mains peaks of the $\mathrm{LaCrO}_{3-\delta}$ orthorhombic phase.

Rietveld refinement was performed to obtain the variation of the crystal lattice volume for each sample after all treatments (Figure S2). Upon reduction, the volume of all samples decreased. This is explained by the formation of oxygen vacancies. Both reducing treatments produced similar behavior and besides the shrinkage due to the formation of oxygen vacancies, no other effect related to exsolution of particles is observed.

The reducing treatment at $750{ }^{\circ} \mathrm{C}$ did not induce significant changes in the morphology and surface of the samples (Figure 2a). This result was expected since $\mathrm{LaCrO}_{3-\delta}$ is highly refractory [39] and $750{ }^{\circ} \mathrm{C}$ is lower than the typical temperature used to induce exsolution $[10,15,16]$. In contrast, after the reduction treatment at $850{ }^{\circ} \mathrm{C}$, the formation of nanoparticles onto the surfaces of larger grains is readily observed (Figure 2b). The nanoparticles have spherical shape and sizes ranging from 20 to $50 \mathrm{~nm}$. The estimated particle sizes are consistent with previously reported data on exsolved 
nanoparticles in Sr-doped lanthanum chromite [10,16,38]. It is possible to observe some

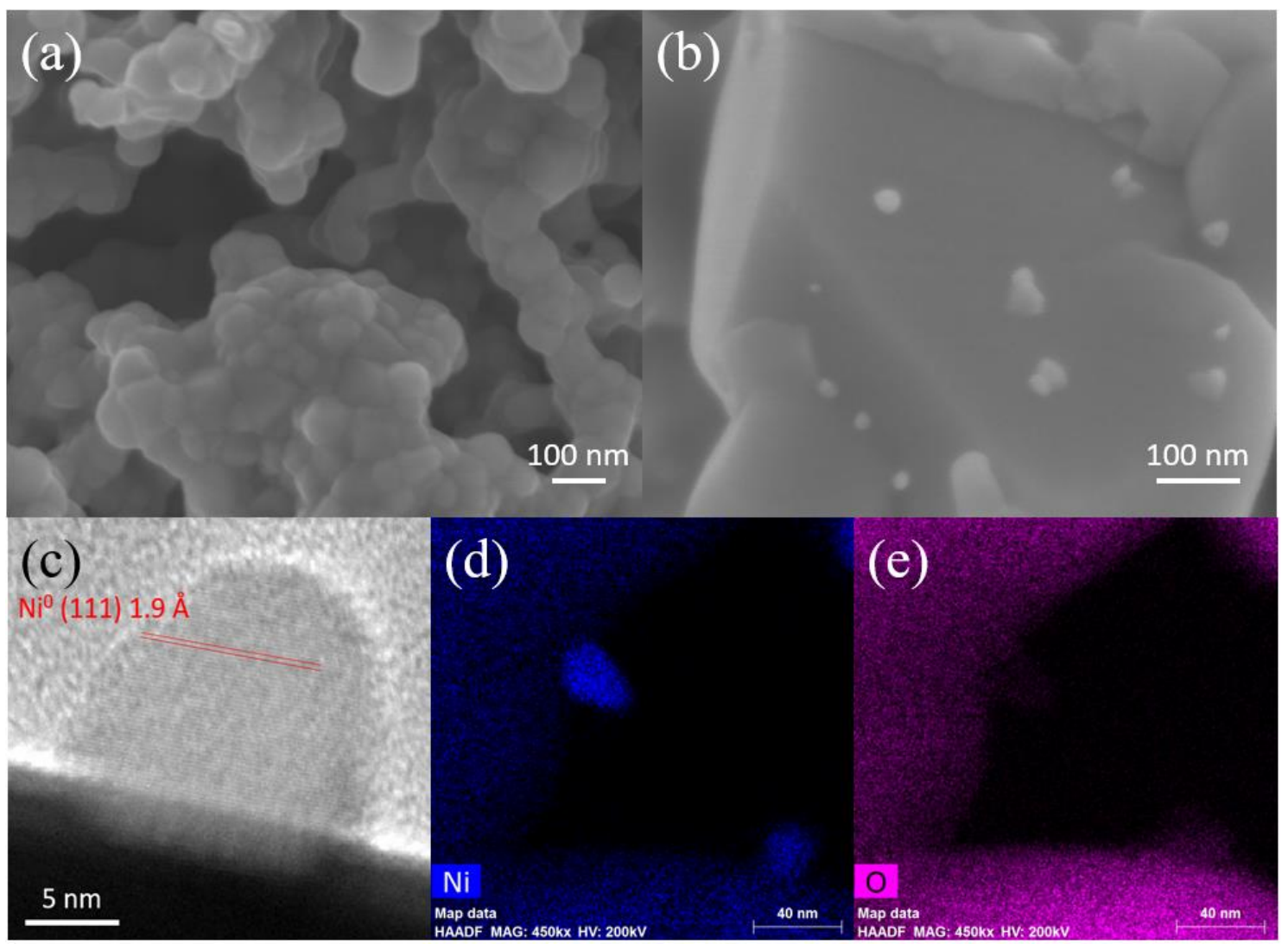

Figure 2: SEM images of the $\left(\mathrm{La}_{0.9} \mathrm{Sr}_{0.1}\right)\left(\mathrm{Cr}_{0.8} \mathrm{Ni}_{0.2}\right) \mathrm{O}_{3-\delta}$ sample reduced at $750{ }^{\circ} \mathrm{C}$ (a) and $850{ }^{\circ} \mathrm{C}$ (b); High-Resolution TEM (HRTEM) images (c); TEM EDX maps of Ni (d) and $\mathrm{O}(\mathrm{e})$.

The HRTEM image shows an isolated nanoparticle on the ceramic surface (Figure 2c). Its fringes distance corresponds to $1.9 \AA$, a value that can be associated with the metallic nickel (111) interplane distance. The TEM energy-dispersive X-ray (EDX) maps of $\mathrm{Ni}$ and $\mathrm{O}$ are shown in Figure2d-e. Such maps clearly reveal that the surface protuberance is an exsolved Ni nanoparticles with a clear compositional difference from the $\mathrm{Sr}$-doped $\mathrm{LaCrO}_{3-\delta}$. They also indicate that these particles are made by metallic nickel since only a weak oxygen signal is observed on the particle's location, probably due to a thin surface oxide layer.

Figure $\mathrm{S} 3 \mathrm{a}$ shows HR-TEM images for the sample $\left(\mathrm{La}_{0.8} \mathrm{Sr}_{0.2}\right)\left(\mathrm{Cr}_{0.8} \mathrm{Ni}_{0.2}\right) \mathrm{O}_{3-\delta}$ after the reducing treatment at $850{ }^{\circ} \mathrm{C}$. The interface between a nanoparticle and the ceramic 
substrate is clearly identified. The image shows a well-defined organization of the atoms planes, respectively. The Fast Fourier Transformation (FFT) from the selected area (Figure S3b) confirms the observed interplanar distances and crystal alignment. Both images show characteristic of a coherent orientation between the $\mathrm{Ni}$ nanoparticle and the ceramic matrix, as expected from exsolved nanoparticles [25]. In Figure S3b, it is possible to observe that the angle between the particle and the lanthanum chromite crystal planes is $45^{\circ}$, providing similar atomic distances on the interface between metal and perovskite. The crystalline planes of the particle are oriented in a direction that minimizes the misfit between the metallic nickel and the lanthanum chromite lattice. While this is expected for nanoparticles originated via exsolution [10], crystal orientation between Ni metallic nanoparticles and the ceramic support is unlikely to be achieved by impregnated/segregated $\mathrm{NiO}$. This observation is a compelling evidence that $\mathrm{Ni}$ nanoparticles have been exsolved from the $\mathrm{Sr}$-doped $\mathrm{LaCrO}_{3-\delta}$ matrix $[10,11]$.

In Figure 3 magnetization curves $(\mathrm{MxH})$ at $117^{\circ} \mathrm{C}$ of both as-prepared samples and the reduced ones at $750{ }^{\circ} \mathrm{C}$ evidence a paramagnetic behavior. The substitution of $\mathrm{Cr}$ for $\mathrm{Ni}$ in the Sr-doped $\mathrm{LaCrO}_{3-\delta}$ structure induces a slight increase in the specific magnetization of the samples. The magnetic structure of the $\mathrm{LaSrCrO}_{3-\delta}$ can be altered by doping, a feature previously observed by replacing ions in the chromite structure [32]. The doping also explains why a weak ferromagnetic component is observed in all compositions, even after calcination at $1000{ }^{\circ} \mathrm{C}$ (Figure 3). It is known that the addition of dopants in the lanthanum chromite, like the $\mathrm{Sr}$ and $\mathrm{Ni}$, can create weak ferromagnetic behavior due to distortion of the magnetic arrangement and creation of oxygen vacancies $[32,40]$. However, the $\mathrm{MxH}$ curves of samples reduced at $750{ }^{\circ} \mathrm{C}$ (Figure 3) show no significant differences from the as-prepared samples, indicating that the reducing treatment at $750{ }^{\circ} \mathrm{C}$ did not provide the necessary driving force for the exsolution process.

Moreover, it is important to note that if segregated $\mathrm{NiO}$ was present in the asprepared samples, it would result in an additional strong ferromagnetic component due to metallic nickel nanoparticles after the reducing treatment at $750{ }^{\circ} \mathrm{C}$ (Figure 3). The absence of this contribution further excludes the presence of residual $\mathrm{NiO}$ in the asprepared samples. 

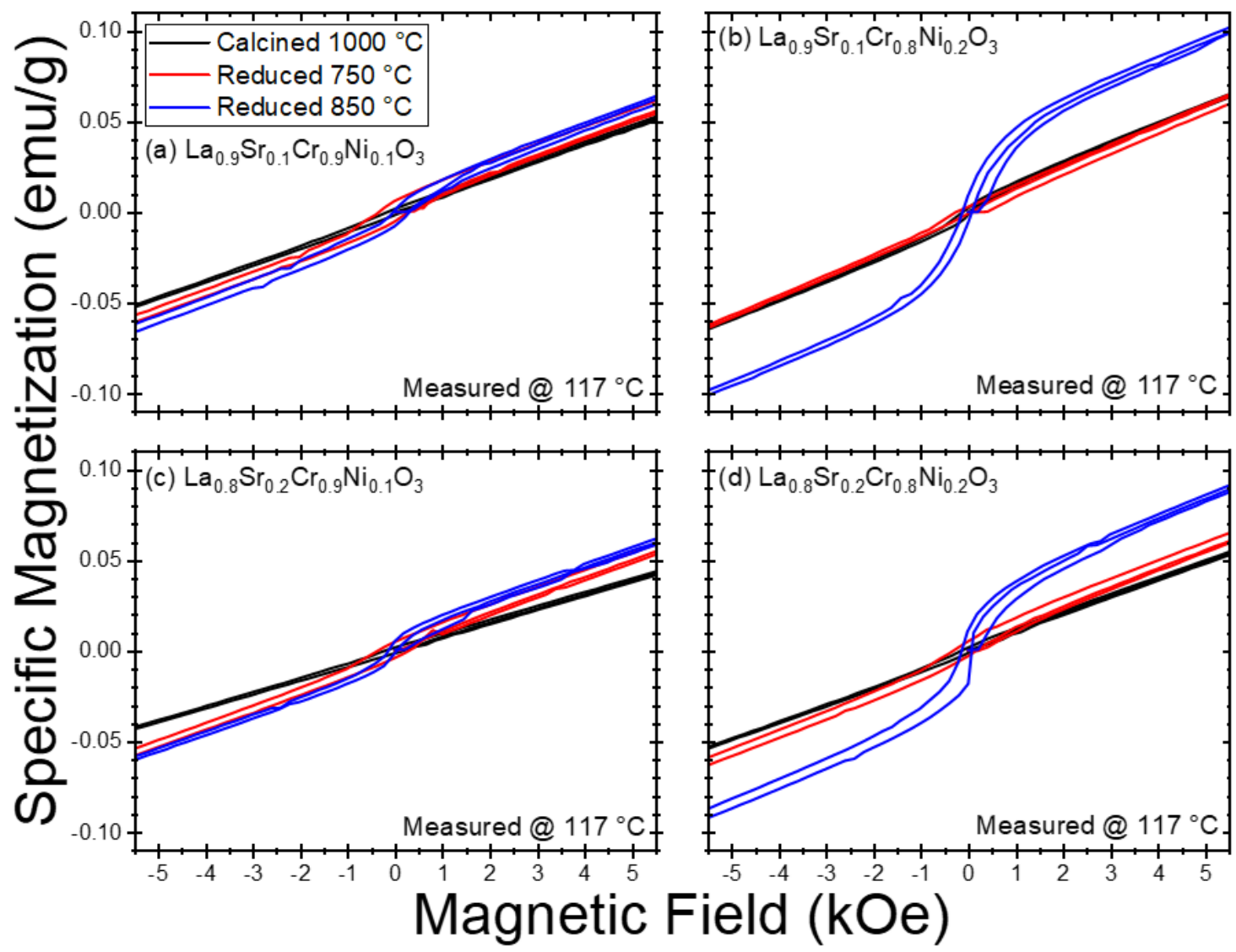

Figure 3: $\mathrm{MxH}$ measured at $117{ }^{\circ} \mathrm{C}$ of the as-prepared samples (black line), reduced at $750{ }^{\circ} \mathrm{C}$ (red line) and reduced at $850{ }^{\circ} \mathrm{C}$ (blue line). The results are from the nominal compositions $\mathrm{La}_{0.9} \mathrm{Sr}_{0.1} \mathrm{Cr}_{0.9} \mathrm{Ni}_{0.1} \mathrm{O}_{3}$ (a), $\mathrm{La}_{0.9} \mathrm{Sr}_{0.1} \mathrm{Cr}_{0.8} \mathrm{Ni}_{0.2} \mathrm{O}_{3}$ (b), $\mathrm{La}_{0.8} \mathrm{Sr}_{0.2} \mathrm{Cr}_{0.9} \mathrm{Ni}_{0.1} \mathrm{O}_{3}$ (c) and $\mathrm{La}_{0.8} \mathrm{Sr}_{0.2} \mathrm{Cr}_{0.8} \mathrm{Ni}_{0.2} \mathrm{O}_{3}(\mathrm{~d})$.

In contrast, the MxH curves in Figure 3 reveal that the reducing treatment at 850 ${ }^{\circ} \mathrm{C}$ resulted in a strong ferromagnetic behavior for the Ni containing specimens, especially on the $20 \%$ Ni-doped compositions. Exsolution is a multistep process that results in the nucleation and growth of nanoparticles on the surface of the hosting material. Both nucleation and growth steps are associated with diffusion of the Ni atoms from within the bulk crystal lattice $[10,15]$ and, thus, are highly dependent on temperature. The increase in the reducing temperature from $750{ }^{\circ} \mathrm{C}$ to $850{ }^{\circ} \mathrm{C}$ led to a significant enhancement in the diffusion of $\mathrm{Ni}^{2+}$ ions in the solid solution, thus enabling efficient exsolution. Nevertheless, it is interesting to note that the temperatures required for exsolution are considerably lower than the ones ( $2 / 3$ melting point) required for net mass diffusion in ceramics, a feature that deserves further studies [41]. 
The ferromagnetic contribution observed in Figure 3 in the samples reduced at 850 images shown in Figure 2. On the other hand, the MxH curves collected for the samples reduced at a lower temperature $\left(750^{\circ} \mathrm{C}\right)$, no changes occur for the sample without $\mathrm{Ni}$, demonstrating that there is no significant change of the $\mathrm{LaSrCrO}_{3}$ ceramic matrix upon reduction (Figure S4).

The magnetization of paramagnetic materials has an almost linear dependence on the applied magnetic field. It follows the equation: $\mathrm{M}=\chi \mathrm{H}$; where $\mathrm{M}$ is the magnetic induction, $\chi$ the magnetic susceptibility and $\mathrm{H}$ the external magnetic field [28]. By considering that the $\mathrm{Sr}$-doped $\mathrm{LaCrO}_{3-8}$ matrix is paramagnetic at $117^{\circ} \mathrm{C}$ it can be easily fitted using a linear function $(y=a x)$. Such a contribution can be subtracted from the $\mathrm{MxH}$ data of Figure 3 to unveil the ferromagnetic contribution of the $\mathrm{Ni}$ exsolved particles. The resulting $\mathrm{MxH}$ curves are shown in Figure 4. Using this subtraction, the ferromagnetic response from the exsolved nickel nanoparticles can be isolated.

Since the particles are not embedded inside of the ceramic matrix, but rather dispersed on its surface the demagnetization factor was not considered. Also, the particles are approximately spherical, isolated [10,11] and on the surface of a paramagnetic compound. For this kind of system, the demagnetization can be considered negligible $[27,28]$. For a polycrystalline powder, the exsolution process produces particles distributed along all the surfaces [14-16], and because of that, the anisotropy effect can also be ignored [28].

Nickel is a canonical ferromagnetic metal and its behavior is well-known. At -273 ${ }^{\circ} \mathrm{C}$ the theoretical saturation magnetization is $57.5 \mathrm{emu} / \mathrm{g}$ and with increasing temperature, at $117{ }^{\circ} \mathrm{C}$, this value drops to $51.014 \mathrm{emu} / \mathrm{g}$ [28]. Thus, by comparing the experimental saturation magnetization with the nominal value for $\mathrm{Ni}$, the mass fraction of metallic $\mathrm{Ni}$ exsolved in the sample can be estimated. The SQUID magnetic measurements enable to quantify extremely low mass fraction with high accuracy, limited by the magnetic measurement's resolution $\left(\sim 10^{-6} \mathrm{emu}\right)$ and sample mass accuracy $(\sim 0.1$ $\mathrm{mg}$ ). 


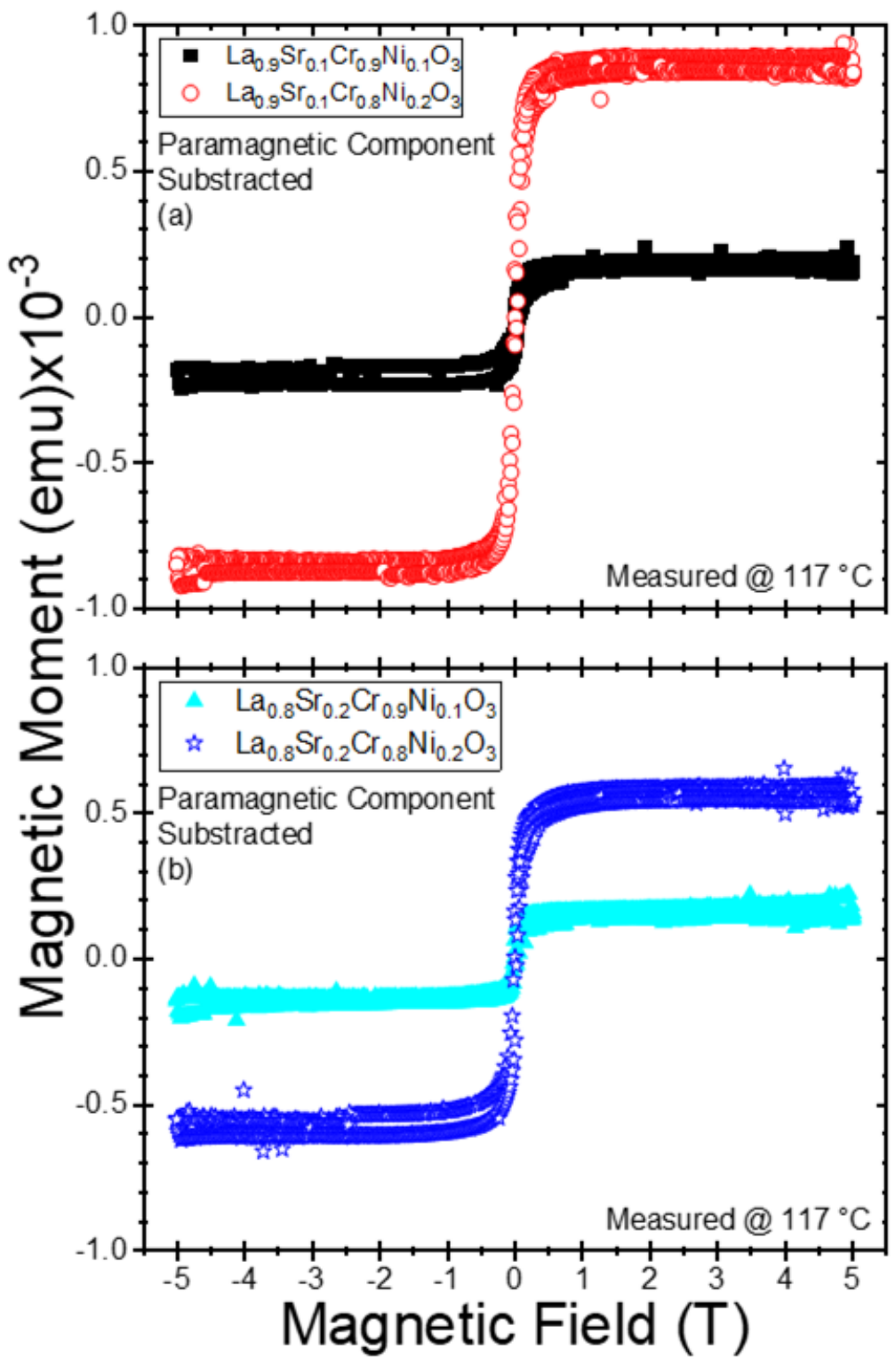

Figure 4: $\mathrm{MxH}$ measured at $117^{\circ} \mathrm{C}$ of the $10 \%$ (a) and $20 \%$ (b) Sr-doped samples after the subtraction of the paramagnetic contribution.

The estimated values of nickel mass fractions obtained from the $\mathrm{MxH}$ data are listed in Table 1. The higher the Ni concentration in the compound (at.\%), the higher is the mass fraction of exsolved nanoparticles. This effect is expected since higher concentrations of nickel ions should facilitate nucleation of particles during the first stage of the exsolution mechanism and later during the growing. 
Table 1: Mass fraction values of metallic nickel calculated from magnetic measurements after the reducing treatment at $850{ }^{\circ} \mathrm{C}$.

\begin{tabular}{ccc}
\hline Samples & Ni mass fraction $(\%)$ & $\mathbf{N i}^{\mathbf{0}} / \mathbf{N i}^{2+}(\%)$ \\
\hline$\left(\mathrm{La}_{0,9} \mathrm{Sr}_{0,1}\right)\left(\mathrm{Cr}_{0,9} \mathrm{Ni}_{0,1}\right) \mathrm{O}_{3}$ & $0.0216(46)$ & $0,86(18)$ \\
$\left(\mathrm{La}{ }_{0,9} \mathrm{Sr}_{0,1}\right)\left(\mathrm{Cr}_{0,8} \mathrm{Ni}_{0,2}\right) \mathrm{O}_{3}$ & $0.0883(71)$ & $1,77(14)$ \\
$\left(\mathrm{La}_{0,8} \mathrm{Sr}_{0,2}\right)\left(\mathrm{Cr}_{0,9} \mathrm{Ni}_{0,1}\right) \mathrm{O}_{3}$ & $0,0206(74)$ & $0,80(29)$ \\
$\left(\mathrm{La}_{0,8} \mathrm{Sr}_{0,2}\right)\left(\mathrm{Cr}_{0,8} \mathrm{Ni}_{0,2}\right) \mathrm{O}_{3}$ & $0,0704(65)$ & $1,38(13)$ \\
\hline
\end{tabular}

It is interesting to note that increasing $\mathrm{Sr}$ content in the $\mathrm{LaCrO}_{3-\delta}$ perovskite inhibits the exsolution of Ni. This is in accordance with previously reported data, which showed that increasing $\mathrm{Sr}$ content in the parent compound resulted in smaller size and concentration of exsolved particles [38]. Such a feature was related to the lattice distortion caused by the incorporation of $\mathrm{Sr}$ in the host perovskite lattice that induces strain fields that hinder the diffusion of nickel atoms.

After the reduction at $850{ }^{\circ} \mathrm{C}$ less than 2 at.\% of the nickel in solid solution was exsolved (Table 1). Obviously, since a reducing atmosphere is needed to promote the reduction of nickel in solid solution, the most superficial layers are more susceptible to the exsolution process rather than the bulk. Also, previous studies had shown that the exsolution process only occurs on the surface of the material. It was proposed that this mechanism is strain-driven and only particles close to the surface can nucleate and grow $[11,15]$. Due to these features, only the $\mathrm{Ni}^{2+}$ close to the surface is prone to reduction and formation of $\mathrm{Ni}^{0}$. Because of that only in the superficial layers occurs the nucleation and diffusion responsible the formation of the exsolved particle, while the $\mathrm{Ni}^{2+}$ in the bulk remains in a stable solid solution (Figure $\mathrm{S} 5)$. Therefore, only a small $\mathrm{Ni}^{0} / \mathrm{Ni}^{2+}$ ratio $(<2$ $\%$ ) is observed for the samples after the reduction at $850{ }^{\circ} \mathrm{C}$.

It is interesting to note that the $\mathrm{Ni}^{0} / \mathrm{Ni}^{2+}$ ratio varies with nickel concentration. Actually, the $\mathrm{Ni}^{0} / \mathrm{Ni}^{2+}$ ratio of the $10 \% \mathrm{Ni}$-doped samples is approximately half of the 20 $\%$ Ni-doped ones. Tae-Sik Oh et al. [15] have shown that the nucleation, which is a critical step in the formation of nanoparticles via exsolution, occurs in a limited depth below the matrix surface. A strain field is formed around the seed nuclei that drive the diffusion of the $\mathrm{Ni}^{2+}$ ions and promote further growth of the nanoparticles in the subsurface region. Eventually, above a critical particle size, accumulation of stress leads to the expulsion of the particles to the surface. In a simple model, one can assume that the 
density of seed nuclei is proportional to $\mathrm{Ni}^{2+}$ concentration. Moreover, considering that each nucleus creates a strain field of fixed volume, which is roughly independent of $\mathrm{Ni}^{2+}$ concentration, then the total amount of $\mathrm{Ni}^{2+}$ that will contribute to nanoparticle growth and be reduced will be proportional to the nuclei density and, consequently, proportional to the square of the original $\mathrm{Ni}^{2+}$ concentration. In other words, the $\mathrm{Ni}^{0} / \mathrm{Ni}^{2+}$ ratio will be proportional to the concentration. (Figure S5). This simple model could explain why the $10 \% \mathrm{Ni}$-doped samples exsolved only approximately half of the $\mathrm{Ni}^{0} / \mathrm{Ni}^{2+}$ ratio when compared with the $20 \% \mathrm{Ni}$-doped samples.

\section{CONCLUSIONS}

The exsolution of Ni nanoparticles from a perovskite matrix lattice was observed and quantitatively analyzed by means of magnetic measurements and electron microscopy analyses. Single-phase lanthanum chromite samples doped with $\mathrm{Sr}$ and $\mathrm{Ni}$ were successfully synthesized. No segregation of $\mathrm{NiO}$ was observed in the as-prepared samples after reduction at $750{ }^{\circ} \mathrm{C}$ under hydrogen. The combination of a paramagnetic matrix, resistant to reducing environments at high temperature, and an exsolved ferromagnetic metal allowed for the successful quantification of exsolved nanoparticles by magnetic measurements. The exsolution process was activated at a temperature close to $850{ }^{\circ} \mathrm{C}$. Increasing of nickel doping in $\mathrm{Sr}-\mathrm{LaCrO}_{3-\delta}$ resulted in an increased mass fraction of Ni particles exsolved. A higher level of strontium doping was observed to hinder the exsolution of Ni nanoparticles. XRD technique has proven not suitable for the characterization of exsolved systems. However, the characterization of exsolved ferromagnetic nanoparticles by magnetic measurements is a rather quick and extremely sensitive method to gain relevant information about nanostructured exsolved systems.

\section{ACKNOWLEDGEMENTS}

The authors acknowledge to CEM (UFABC). VBT acknowledges FAPESP (2015/23899-4) for scholarship. DZF acknowledges to CNPq (309600/2018-9) and FAPESP (2015/24999-2). Authors gratefully acknowledge the support form RCGI Shell (ANP)/FAPESP (grant 2014/50279-4), and CINE Shell (ANP)/FAPESP (grant 2017/11937-4). FCF, DZF, and ASF are CNPq fellows.

\section{REFERENCES}

[1] S.M. Lindsay, Introduction to Nanoscience, Nano Today. 3 (2008) 47. 
doi:10.1016/S1748-0132(08)70046-X.

[2] M.M. Khin, A.S. Nair, V.J. Babu, R. Murugan, S. Ramakrishna, A review on nanomaterials for environmental remediation, Energy Environ. Sci. 5 (2012) 8075. doi:10.1039/c2ee21818f.

[3] D. Bagchi, M. Bagchi, H. Moriyama, F. Shahidi, Bio-Nanotechnology: A Revolution in Food, Biomedical and Health Sciences, 2013. doi:10.1002/9781118451915.

[4] V. Esposito, C. Gadea, J. Hjelm, D. Marani, Q. Hu, K. Agersted, S. Ramousse, S.H. Jensen, Fabrication of thin yttria-stabilized-zirconia dense electrolyte layers by inkjet printing for high performing solid oxide fuel cells, J. Power Sources. 273 (2015) 89-95. doi:10.1016/j.jpowsour.2014.09.085.

[5] D. Marani, C. Gadea, J. Hjelm, P. Hjalmarsson, M. Wandel, R. Kiebach, Influence of hydroxyl content of binders on rheological properties of ceriumgadolinium oxide (CGO) screen printing inks, J. Eur. Ceram. Soc. 35 (2015) 1495-1504. doi:10.1016/j.jeurceramsoc.2014.11.025.

[6] R. Narayan, Use of nanomaterials in water purification, Mater. Today. 13 (2010) 44-46. doi:10.1016/S1369-7021(10)70108-5.

[7] M.K. Nayak, J. Singh, B. Singh, S. Soni, V.S. Pandey, S. Tyagi, Introduction to semiconductor nanomaterial and its optical and electronics properties, in: Met. Semicond. Core-Shell Nanostructures Energy Environ. Appl., Elsevier, 2017: pp. 1-33. doi:10.1016/B978-0-323-44922-9.00001-6.

[8] D. Burnat, R. Kontic, L. Holzer, P. Steiger, D. Ferri, A. Heel, Smart material concept: reversible microstructural self-regeneration for catalytic applications, J. Mater. Chem. A. 4 (2016) 11939-11948. doi:10.1039/C6TA03417A.

[9] D. Marani, R.H. Silva, A. Dankeaw, K. Norrman, R.M.L. Werchmeister, D. Ippolito, M. Gudik-Sørensen, K.K. Hansen, V. Esposito, NOx selective catalytic reduction (SCR) on self-supported V-W-doped TiO 2 nanofibers, New J. Chem. 41 (2017) 3466-3472. doi:10.1039/C6NJ03205B.

[10] D. Neagu, T.-S. Oh, D.N. Miller, H. Ménard, S.M. Bukhari, S.R. Gamble, R.J. Gorte, J.M. Vohs, J.T.S. Irvine, Nano-socketed nickel particles with enhanced 
coking resistance grown in situ by redox exsolution, Nat. Commun. 6 (2015) 8120. doi:10.1038/ncomms9120.

[11] L. Thommy, O. Joubert, J. Hamon, M.-T. Caldes, Impregnation versus exsolution: Using metal catalysts to improve electrocatalytic properties of LSCM-based anodes operating at $600{ }^{\circ} \mathrm{C}$, Int. J. Hydrogen Energy. 41 (2016) 14207-14216. doi:10.1016/j.ijhydene.2016.06.088.

[12] T.S. Rodrigues, A.B.L. de Moura, F.A. e Silva, E.G. Candido, A.G.M. da Silva, D.C. de Oliveira, J. Quiroz, P.H.C. Camargo, V.S. Bergamaschi, J.C. Ferreira, M. Linardi, F.C. Fonseca, Ni supported Ce0.9Sm0.1O2- $\delta$ nanowires: An efficient catalyst for ethanol steam reforming for hydrogen production, Fuel. 237 (2019) 1244-1253. doi:10.1016/j.fuel.2018.10.053.

[13] A.S. Ferlauto, D.Z. de Florio, F.C. Fonseca, V. Esposito, R. Muccillo, E. Traversa, L.O. Ladeira, Chemical vapor deposition of multi-walled carbon nanotubes from nickel/yttria-stabilized zirconia catalysts, Appl. Phys. A. 84 (2006) 271-276. doi:10.1007/s00339-006-3617-x.

[14] Y.-F. Sun, Y.-Q. Zhang, J. Chen, J.-H. Li, Y.-T. Zhu, Y.-M. Zeng, B.S. Amirkhiz, J. Li, B. Hua, J.-L. Luo, New Opportunity for in Situ Exsolution of Metallic Nanoparticles on Perovskite Parent, Nano Lett. 16 (2016) 5303-5309. doi:10.1021/acs.nanolett.6b02757.

[15] T.-S. Oh, E.K. Rahani, D. Neagu, J.T.S. Irvine, V.B. Shenoy, R.J. Gorte, J.M. Vohs, Evidence and Model for Strain-Driven Release of Metal Nanocatalysts from Perovskites during Exsolution, J. Phys. Chem. Lett. 6 (2015) 5106-5110. doi:10.1021/acs.jpclett.5b02292.

[16] D. Papargyriou, J.T.S. Irvine, Nickel nanocatalyst exsolution from (La,Sr) (Cr,M,Ni)O 3 (M Mn,Fe) perovskites for the fuel oxidation layer of Oxygen Transport Membranes, Solid State Ionics. 288 (2016) 120-123. doi:10.1016/j.ssi.2015.11.007.

[17] Y. Nishihata, J. Mizuki, T. Akao, H. Tanaka, M. Uenishi, M. Kimura, T. Okamoto, N. Hamada, Self-regeneration of a Pd-perovskite catalyst for automotive emissions control, Nature. 418 (2002) 164-167. doi:10.1038/nature00893. 
[18] N.K. Monteiro, F.B. Noronha, L.O.O. da Costa, M. Linardi, F.C. Fonseca, A direct ethanol anode for solid oxide fuel cell based on a chromite-manganite with catalytic ruthenium nanoparticles, Int. J. Hydrogen Energy. 37 (2012) 98169829. doi:10.1016/j.ijhydene.2012.03.157.

[19] Y. Zhu, W. Zhou, R. Ran, Y. Chen, Z. Shao, M. Liu, Promotion of Oxygen Reduction by Exsolved Silver Nanoparticles on a Perovskite Scaffold for LowTemperature Solid Oxide Fuel Cells, Nano Lett. 16 (2016) 512-518. doi:10.1021/acs.nanolett.5b04160.

[20] J. Sunarso, S.S. Hashim, N. Zhu, W. Zhou, Perovskite oxides applications in high temperature oxygen separation, solid oxide fuel cell and membrane reactor: A review, Prog. Energy Combust. Sci. 61 (2017) 57-77. doi:10.1016/j.pecs.2017.03.003.

[21] H.M. Rietveld, A profile refinement method for nuclear and magnetic structures, J. Appl. Crystallogr. 2 (1969) 65-71. doi:10.1107/S0021889869006558.

[22] J. Epp, X-ray diffraction (XRD) techniques for materials characterization, in: Mater. Charact. Using Nondestruct. Eval. Methods, Elsevier, 2016: pp. 81-124. doi:10.1016/B978-0-08-100040-3.00004-3.

[23] B.D. Cullity, Elements of X-ray diffraction, 2nd edition, Addison-Wesley Publ. Co. Read. MA. (1978) 100-105,277-279. doi:10.1119/1.1934486.

[24] R.F. Egerton, Physical principles of electron microscopy: An introduction to TEM, SEM, and AEM, second edition, 2016. doi:10.1007/978-3-319-39877-8.

[25] D. Neagu, G. Tsekouras, D.N. Miller, H. Ménard, J.T.S. Irvine, In situ growth of nanoparticles through control of non-stoichiometry, Nat. Chem. 5 (2013) 916923. doi:10.1038/nchem.1773.

[26] Y. Sun, J. Li, Y. Zeng, B.S. Amirkhiz, M. Wang, Y. Behnamian, J. Luo, A-site deficient perovskite: the parent for in situ exsolution of highly active, regenerable nano-particles as SOFC anodes, J. Mater. Chem. A. 3 (2015) 11048-11056. doi:10.1039/C5TA01733E.

[27] L. Zhao, N.. van Dijk, E. Brück, J. Sietsma, S. van der Zwaag, Magnetic and Xray diffraction measurements for the determination of retained austenite in TRIP 
steels, Mater. Sci. Eng. A. 313 (2001) 145-152. doi:10.1016/S09215093(01)00965-0.

[28] B.D. Cullity, C.D. Graham, Introduction to magnetic materials, Mater. Today. 12 (2009) 45. doi:10.1016/S1369-7021(09)70091-4.

[29] C. Solís, L. Navarrete, M. Balaguer, J.M. Serra, Development and understanding of $\mathrm{La} 0.85 \mathrm{Sr} 0.15 \mathrm{Cr} 1-\mathrm{xNixO} 3-\delta$ anodes for La5.6WO11.4- $\delta$-based Proton Conducting Solid Oxide Fuel Cells, J. Power Sources. 258 (2014) 98-107. doi:10.1016/j.jpowsour.2014.02.015.

[30] L. GROUPP, H.U. ANDERSON, Densification of La1- xSixCrO3, J. Am. Ceram. Soc. 59 (1976) 449-450. doi:10.1111/j.1151-2916.1976.tb09517.x.

[31] G.-Y. Lee, R.-H. Song, J.-H. Kim, D.-H. Peck, T.-H. Lim, Y.-G. Shul, D.-R. Shin, Properties of $\mathrm{Cu}, \mathrm{Ni}$, and $\mathrm{V}$ doped-LaCrO 3 interconnect materials prepared by pechini, ultrasonic spray pyrolysis and glycine nitrate processes for SOFC, J. Electroceramics. 17 (2006) 723-727. doi:10.1007/s10832-006-0473-1.

[32] K. Tezuka, Y. Hinatsu, A. Nakamura, T. Inami, Y. Shimojo, Y. Morii, Magnetic and Neutron Diffraction Study on Perovskites La1-xSrxCrO3, J. Solid State Chem. 141 (1998) 404-410. doi:10.1006/jssc.1998.7961.

[33] M.P. Pechini, Method of preparing lead and alkaline earth titanates and niobates and coating method using the same to form a capacitor, 1967. http://scholar.google.com/scholar?hl=en\&btnG=Search\&q=intitle:Method+of+pr eparing+lead+and+alkaline+earth+titanates+and+niobates+and+coating+method +using+the+same+to+form+a+capactor\#0.

[34] D. Segal, Chemical synthesis of ceramic materials, J. Mater. Chem. 7 (1997) 1297-1305. doi:10.1039/a700881c.

[35] L.-W. Tai, P.A. Lessing, Modified resin-intermediate processing of perovskite powders: Part I. Optimization of polymeric precursors, J. Mater. Res. 7 (1992) 502-510. doi:10.1557/JMR.1992.0502.

[36] K. V. Manukyan, A.G. Avetisyan, C.E. Shuck, H.A. Chatilyan, S. Rouvimov, S.L. Kharatyan, A.S. Mukasyan, Nickel Oxide Reduction by Hydrogen: Kinetics and Structural Transformations, J. Phys. Chem. C. 119 (2015) 16131-16138. 
doi:10.1021/acs.jpcc.5b04313.

[37] R.W. Simmonds, Quantum interference heats up, Nature. 492 (2012) 358-359. doi:10.1038/492358a.

[38] V.B. Vert, F. V. Melo, L. Navarrete, J.M. Serra, Redox stability and electrochemical study of nickel doped chromites as anodes for $\mathrm{H} 2 / \mathrm{CH} 4$-fueled solid oxide fuel cells, Appl. Catal. B Environ. 115-116 (2012) 346-356. doi:10.1016/j.apcatb.2011.12.033.

[39] M. Mori, Sintering behavior of $\mathrm{Ca}$ - or $\mathrm{Sr}$-doped $\mathrm{LaCrO} 3$ perovskites including second phase of AECrO4 (AE=Sr, Ca) in air, Solid State Ionics. 135 (2000) 743 748. doi:10.1016/S0167-2738(00)00372-6.

[40] Z. Wen, Y. Cui, Y. Chen, Y. Zhao, Effect of Ca Doping on the Structure and

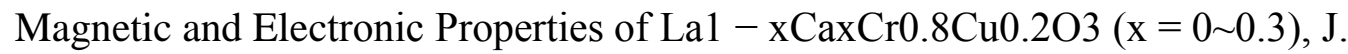
Supercond. Nov. Magn. 32 (2019) 2655-2660. doi:10.1007/s10948-019-5003-x.

[41] V. Esposito, D.W. Ni, D. Marani, F. Teocoli, K.T.S. Thydén, D.Z. De Florio, F.C. Fonseca, Accelerated ceria-zirconia solubilization by cationic diffusion inversion at low oxygen activity, J. Mater. Chem. A. 4 (2016). doi:10.1039/c6ta06308j.

[42] T.J.B. W. M. Haynes, David R. Lide, CRC Handbook of Chemistry and Physics, 97th ed., CRC Press, 2016. 
Click here to access/download

\section{Supporting Information
upporting_Information.docx Supporting Information
Supporting_Information.docx}

